\title{
Summary of: \\ Public awareness and social acceptability of dental therapists
}

\author{
T. A. Dyer, ${ }^{1}$ G. Humphris ${ }^{2}$ and P. G. Robinson ${ }^{3}$
}

\section{FULL PAPER DETAILS}

1 "Lecturer in Dental Public Health, ${ }^{3}$ Professor of Dental Public Health, Department of Oral Health and Development, School of Clinical Dentistry, University of Sheffield, Claremont Crescent, Sheffield, S10 2TA: 2Professor of Health Psychology, University of St Andrews, St Andrews, Fife, KY169TS

*Correspondence to: Dr Thomas A. Dyer

Email:t.dyer@sheffield.ac.uk

Online article number E2

Refereed Paper - Accepted 25 August 2009

DOI: 10.1038/sj.bdj.2010.1

British Dental Journal 2010; 208: E2

Objectives To investigate public awareness and the social acceptability of dental treatment provided by dental therapists in the UK. Method A telephone survey of a representative quota sample of 1,000 UK adults. Results $10.4 \%$ of participants were aware of dental therapists as a professional group, of whom none correctly identified their permitted duties. 61.3\% were willing to receive simple restorative treatment from a therapist, with acceptability predicted by being male [OR 1.44 (95\% Cl 1.09-1.90)], being younger [OR 1.024 (1.016-1.032)] and having a perceived need for treatment [OR 1.49 (1.09-2.5)]. Fewer were willing to allow a therapist to restore a child's tooth (54.7\%, $p<0.001$, McNemar's test) with acceptability predicted by being younger [OR $1.026(1.018-1.034)]$. Those receiving some private treatment were less likely to report acceptability of simple restorative treatment for themselves [OR 0.61 (0.46-0.81)] or for children [OR 0.54 (0.41-0.72)]. 48.2\% of participants expected to pay less for treatment provided by therapists, with acceptability of equal costs predicted by the participant being male [OR 1.81 (1.50-2.40)]. Conclusion These findings identify a need for education and reassurance of the public on the training and permitted duties of dental therapists and the rationale for skill-mix in dentistry.

\section{EDITOR'S SUMMARY}

We have published quite a range of material in recent times on the role of dental therapists within the skill mix of current and envisaged dental care delivery in the UK, which may also inform that in other countries too. To date, this has focussed on the views and understanding of fellow dental professionals towards the place, role, competencies and value of dental therapists but has taken scant account of the patient's perspective.

Publication of this paper seeks to redress that situation and indeed provides some interesting insights not only into the public's perception but also, possibly, underlines some of our own attitudes towards care provided by those other than the team leader.

Given that dental therapists are still a very tiny group within the dental workforce it is hardly surprising that few knew of their areas of work. Once their competencies were explained a majority of people indicated that they would be prepared to accept simple restorative care from therapists but significantly, I think, there was resistance from those who were having private care. Similarly, there was an expectation that treatment would cost less when delivered by a therapist.

I cannot help wondering if this is coloured by the perception that the treatment provided is somehow of a lesser value than that of, say, a dentist? Of course it is not of lesser value but this is also a misconception that we need to correct within the dental team itself. We clearly need to educate our patients about this and to emphasise that the care provided by therapists is honed precisely because it is circumspect rather than that it is limited because they are less competent. We frequently devolve to comparisons with medicine and the rise in the use of practice nurses, for example. Few of us would request that 'the doctor' took our blood, or gave us vaccinations in preference to the nurse and I suggest that we need to elevate the value of the dental therapist to a similar position of worth within clinical dentistry if they are to become successfully integrated members of the workforce.

The full paper can be accessed from the $B D J$ website (www.bdj.co.uk), under 'Research' in the table of contents for Volume 208 issue 1.

Stephen Hancocks, Editor in Chief

DOI: 10.1038/sj.bdj.2010.25 
TO ACCESS THE BDJ WEBSITE TO READ THE FULL PAPER:

- BDA Members should go to www.bda.org.

- Click the 'login' button on the right-hand side and enter your BDA login details.

- Once you have logged in click the 'BDJ' tab to transfer to the BDJ website with full access.

IF YOUR LOGIN DETAILS DO NOT WORK:

- Get a password reminder: go to www.bda.org, click the login button on the right-hand side and then click the forgotten password link.

- Use a recommended browser: we recommend Microsoft Internet Explorer or Mozilla Firefox.

- Ensure that the security settings on your browser are set to recommended levels.

IF YOU HAVE NOT YET SIGNED UP TO USE THE BDA WEBSITE:

- Go to www.bda.org/getstarted for information on how to start using the BDA website.
IN BRIEF

- Awareness of dental therapists and their permitted duties in the UK is low.

- Nearly two thirds of participants accepted the possibility of receiving fillings from therapists.

- Fewer people were willing for their children to receive treatment from therapists.

- Public education and reassurance is needed on the training and permitted duties of therapists and the rationale for skill-mix in dentistry.

\section{COMMENT}

The role of dually qualified dental hygienist-therapists (therapists) is continuing to develop, with a number of training programmes now long-established throughout the UK. Several of these have progressed to degree programmes offering a BSc in Oral Health Sciences in recognition of the academic content and broad clinical element of the curriculum.

However, therapists remain a relatively small proportion of the workforce (1 per 60,000) and therefore few members of the public could be expected to have had contact with, or received treatment from them. Previous work has demonstrated that there is a significant lack of knowledge amongst dentists about the role and clinical remit of therapists, so it is perhaps not surprising that knowledge amongst the public interviewed in this study was similarly scant. However, it was reassuring to note that following a description of the role of the therapist by the interviewer, in excess of $60 \%$ of respondents would be willing to accept treatment. It would seem that it may not be public perception which will restrict the use of therapists in the future but the way in which they are employed. Historically, a similar situation existed with the development of the dental hygienist, who are now almost 5,000 strong and are a well-valued and respected member of the team. Indeed they are viewed by many as being indispensable to successful practice.

The delivery of dentistry in the UK is probably undergoing its most major modernisation process to date. A number of new groups of professionals is emerging, all with a role to play in the treatment of patients. Examples of these are clinical dental technicians and orthodontic therapists, who will also have to be recognised by dentists and public alike for skill-mix to be successful. Therapists are skilled clinicians who have the ability to undertake much of the work encountered in general dental practice, but they must be positively embraced to be of maximum benefit to patients and the profession at large. There is a distinct need to promote therapists widely amongst the profession and public, as they have a major contribution to make to patient care. It is vital that they are not depicted as being a less qualified clinician, but more as one in whom education has been invested to produce a robust professional, well able and competent to provide routine dentistry thus allowing dentists to focus on the more specialised skills received in their education. Public acceptability may be important but, with the correct approach, may not prove to be a serious barrier to the development of teamworking and skillmix. It is clearly not who delivers care that is in question, but the quality of care which is provided to the public.

\section{Ross}

Senior Lecturer, Edinburgh Postgraduate Dental Institute

\section{AUTHOR QUESTIONS AND ANSWERS}

1. Why did you undertake this research? The last decade has seen greater emphasis on the use of skill-mix in dentistry. The rationale is to maximise efficiency and access while maintaining other aspects of the quality of dental care. Consequently, legislation now allows dental therapists to work in all sectors of healthcare and there has also been an increase in training places. Although dentists' awareness and acceptance of dental therapists is increasing, little is known of the public's views. With the intention to increase the use of skill-mix, knowledge of the levels of public awareness and acceptability is essential. Information on the types of people most/least willing to be seen by therapists would assist in devising and targeting information campaigns on the use of skill-mix.

2. What would you like to do next in this area to follow on from this work?

Although our findings have a number of important implications for policymakers and the dental profession, we are particularity interested in exploring the views of patients, and parents/carers of patients, who have received treatment from dental therapists. Although there are anecdotal reports of high levels of patient satisfaction with care received, there are no published UK data. For example, what are the views of patients on treatment received from dental therapists and what influences their views? Ideally this research should consider the use of skill-mix in the NHS and private sector and for the treatment of adults and children and would use a mixedmethod approach. 